\title{
Prevalence of Depressive Symptoms among Elderly People residing in Nursing Homes of Baghdad City/ Iraq
}

\author{
Dr. Maan Hameed Ibrahim Al-Ameri \\ ${ }^{I}$ PhD, Assist. Professor Psychiatric Mental Health Department, College of Nursing, University of Baghdad)
}

\begin{abstract}
Aging is a series of processes that begin with life and continue throughout the life cycle. As persons grow older, they are encountered various physical, psychological and social role changes that challenge their sense of self and ability to live happily. Depression is considered to be the main difficulty leading to emotional imbalance and impaired quality of life among elderly individuals. The study aims to find out the prevalence of levels of depressive symptoms among elderly in nursing homes of Baghdad city; and to explore any relationship between levels of depressive symptoms and some socio-demographic characteristics of elderly. A descriptive study was conducted from May $9^{\text {th }}, 2016$ to the August $8^{\text {th }}, 2016$ upon a non-probability sample of 52 elderly who live currently in two nursing homes of Baghdad city; 32 elderly individuals were recruited from Al-Rashad nursing home and other 20 from Al-Salakh nursing home. To meet the aims of the present study a questionnaire was constructed. The questionnaire consisted of two parts: firstly, five socio-demographic characteristics of elderly: gender, age, level of education, occupation and marital status; and second part is fifteen items which are supposed to assess levels of depressive symptoms and represent Geriatric Depression Scale (GDS-15) for Almeida (1999) $)^{(1)}$ which is to define the levels of depressive symptoms among those elderly. Data were analysed by method of: a descriptive statistical analysis: frequencies and percentages and tables of distribution; and inferential analysis which was Chi ${ }^{2}$. The present study indicates that $75.0 \%$ of elderly participated are male; about half of them are married; about $70.0 \%$ are 60 years old and more; $63.1 \%$ of them have secondary school and more level of education; about half of participants are retired. The results also reveals too that $76.9 \%$ of elderly have moderate level of depressive symptoms and 19.2\% of those elderly has more severe symptoms and only 3.8\% are within normal level of depressive symptoms. The study finds a significant relationship between level of depressive symptoms and gender and level of education. The present study recommends for more provision of mental health services for elderly in nursing homes. Increasing in the extent psychosocial support services for elderly is necessary; and referral and follow-up for those who have severe levels of depressive symptoms to specialized hospitals. Further researches upon larger samples and within different governorates of the country are to be done.
\end{abstract}

Keyword: prevalence, levels, depressive, symptoms, elderly, nursing, homes, Baghdad.

\section{Introduction}

Depressive symptoms are common problems among older adults ${ }^{(2)}$.Various studies have indicated that around $15 \%$ of those over age 65 experience symptoms of depression that cause them distress and make it hard for them to function ${ }^{(3)}$. In late life, depression affects mainly the elderly with different physical illnesses. In addition, depression not only makes a person feel physically ill, but actually makes physical health worse and increases mortality ${ }^{(4)}$. Depressive symptoms in late-life cause pain and grief not just for those who are depressed, but also for those who care about them and severe depressive symptoms can cause excessive disturbance and misery for the family as well as for the individual who is depressed ${ }^{(5)}$. Depressive symptoms reflect a variety of physical and social factors and it may be challenging to identify in elderly people as its manifestations could vary from that of younger ages ${ }^{(6)}$. The common depressive symptoms, which are not contributed to old age, are a loss of interest in life, lack of enjoyment in normal activities, apprehension, poor sleep, and persistent thoughts of death, chronic unexplained pain, poor concentration or impaired memory ${ }^{(3,7)}$. In conclusion, low socio-economic rank, low educational level and being widowed are socio-demographic causes related to depressive symptoms in the elderly ${ }^{(8.9)}$. It is significant to notice that keeping fit has been associated to the improvement of depressive symptoms and generally health consequences in elderly clients with depressive symptoms ${ }^{(10,11)}$. Depressive symptoms among elderly may be complicated by co-morbid overall medical diseases which regularly outbreak them and they present with a display of physical symptoms that may be as a resulting to the concomitant conditions separately or jointly ${ }^{(12,13)}$.

\section{Objective of the Study}

The present study aims to find out the prevalence of levels of depressive symptoms among elderly people residing in nursing homes of Baghdad city; and furthermore to explore any relationship between these levels of depressive symptoms and some socio-demographic characteristics of elderly people. 


\section{Methodology}

A descriptive study was conducted from May 9th, 2016 to the August 8th, 2016 upon a non-probability sample of 52 elderly who live currently in two nursing homes of Baghdad city; 32 elderly individuals were recruited from Al-Rashad nursing home and other 20 from Al-Salakh nursing home. To meet the aims of the present study a questionnaire was constructed. The questionnaire consisted of two parts: firstly, five sociodemographic characteristics of elderly: gender, age, level of education, occupation and marital status; and second part is fifteen items which are supposed to assess levels of depressive symptoms and represent Geriatric Depression Scale (GDS-15) for Almeida (1999) ${ }^{(1)}$ which is to define the levels of depressive symptoms among those elderly. The 15-item GDS (GDS-15) is a short version of the original Geriatric Depression Scale (GDS), developed by Sheikh \& Yesavage (1986) ${ }^{(15)}$ from items more strongly linked to the recognition of depressive symptoms. Overall, GDS items have revealed good diagnostic accurateness in addition to acceptable understanding, precise and reliability. The GDS short version is fairly an attractive tool for screening depressive symptoms in outpatients in general in addition to other non-specific situations since its application is shorter. 15 to 20 minutes the time needed for each questionnaire to be completed. The researcher completed filling all the questionnaires during interviewing the elderly. Data were analysed by method of: a descriptive statistical analysis: frequencies and percentages and tables of distribution; and inferential analysis which was Chi2.

\section{Results}

Table 1: Distribution of the total sample according to the Demographic Characteristics of the Elderly People participated in the study

\begin{tabular}{|c|c|c|c|c|c|}
\hline \multicolumn{3}{|c|}{ Gender } & \multicolumn{3}{|c|}{ Occupation } \\
\hline Gender & f & $\%$ & & f & $\%$ \\
\hline Male & 39 & $75.0 \%$ & Free work & 15 & $28.8 \%$ \\
\hline Female & 13 & $25.0 \%$ & Retired & 27 & $51.9 \%$ \\
\hline Total & 52 & $100.0 \%$ & House Keeper & 10 & $19.2 \%$ \\
\hline & & & Total & 52 & $100.0 \%$ \\
\hline \multicolumn{3}{|c|}{ Age } & \multicolumn{3}{|c|}{ Level of Education } \\
\hline year & $\mathbf{f}$ & $\%$ & Level & $\mathbf{f}$ & $\%$ \\
\hline $40-49$ & 2 & $3.8 \%$ & Illiterate & 6 & $11.5 \%$ \\
\hline $50-59$ & 14 & $26.9 \%$ & Read and write \& Primary & 13 & $25.0 \%$ \\
\hline $60-69$ & 17 & $32.7 \%$ & Secondary & 21 & $40.0 \%$ \\
\hline$\geq 70$ & 19 & $36.5 \%$ & Institute, college $\&$ more & 12 & $23.1 \%$ \\
\hline Total & 52 & $100.0 \%$ & Total & 52 & $100.0 \%$ \\
\hline \multicolumn{6}{|c|}{ Marital Status } \\
\hline & & & f & \multicolumn{2}{|c|}{$\%$} \\
\hline \multicolumn{3}{|c|}{ Single } & 4 & \multicolumn{2}{|c|}{$7.7 \%$} \\
\hline \multicolumn{3}{|c|}{ Married } & 44 & \multicolumn{2}{|c|}{$84.6 \%$} \\
\hline \multicolumn{3}{|c|}{ Divorced } & 1 & \multicolumn{2}{|c|}{$1.9 \%$} \\
\hline \multicolumn{3}{|c|}{ Widowed } & 3 & \multicolumn{2}{|c|}{$5.8 \%$} \\
\hline \multicolumn{3}{|c|}{ Total } & 52 & \multicolumn{2}{|c|}{$100.0 \%$} \\
\hline
\end{tabular}

The results of table (1) indicates that $75.0 \%$ of elderly participated are male; about half of them are married; about $70.0 \%$ are 60 years old and more; $63.1 \%$ of them have secondary school and more level of education; about half of participants are retired.

Table 2: Distribution of the sample according to the severity of Depressive symptoms

\begin{tabular}{|c|c|c|c|c|}
\hline & Cut-off Points & Levels of Depressive Symptoms & f & \% \\
\hline & $0-4$ & Normal Symptoms & 2 & $3.8 \%$ \\
\cline { 2 - 5 } & $5-9$ & Mild Depressive Symptoms & 40 & $76.9 \%$ \\
\cline { 2 - 5 } & $10-15$ & More Severe Depressive Symptoms & 10 & $19.2 \%$ \\
\cline { 2 - 5 } & Total & $\mathbf{5 2}$ & $\mathbf{1 0 0 . 0}$ \\
\hline
\end{tabular}

Table (2) shows that $76.9 \%$ of elderly have moderate level of depressive symptoms and $19.2 \%$ of those elderly has more severe symptoms and only $3.8 \%$ are within normal level of depressive symptoms.

Table 3: Distribution in levels of depressive symptoms according to the Gender of elderly people

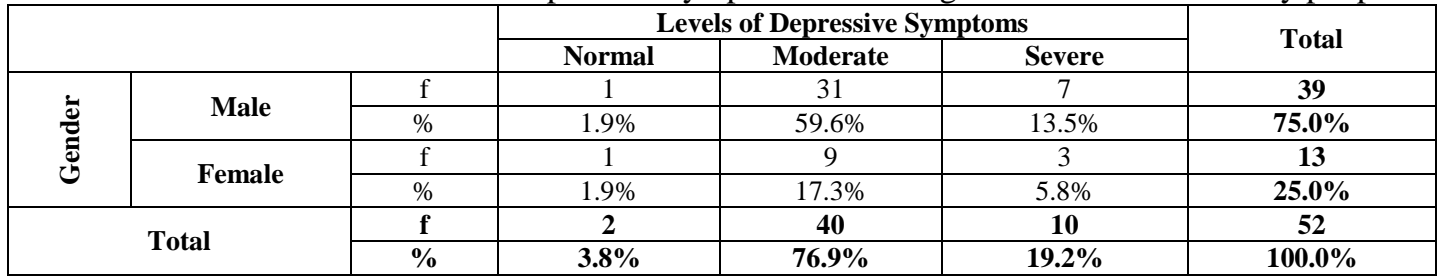

Table (3) shows that $59.6 \%$ of the male elderly and $17.3 \%$ of female have moderate level; and $13.5 \%$ of male and $5.8 \%$ of female have severe level. 
Table 4: Distribution in levels of depressive symptoms according to the Age of elderly people

\begin{tabular}{|c|c|c|c|c|c|c|}
\hline & \multicolumn{3}{|c|}{ Levels of Depressive Symptoms } & \multirow{2}{*}{ Total } \\
\hline & & & Normal & Moderate & Severe & \\
\hline \multirow{8}{*}{$\underset{4}{2}$} & \multirow{2}{*}{ 40-49 } & $\mathrm{f}$ & 0 & 2 & 0 & 2 \\
\hline & & $\%$ & $0.0 \%$ & $3.8 \%$ & $0.0 \%$ & $3.8 \%$ \\
\hline & \multirow{2}{*}{$50-59$} & $\mathrm{f}$ & 0 & 10 & 4 & 14 \\
\hline & & $\%$ & $0.0 \%$ & $19.2 \%$ & $7.7 \%$ & $26.9 \%$ \\
\hline & \multirow[b]{2}{*}{$60-69$} & $\mathrm{f}$ & 0 & 15 & 2 & 17 \\
\hline & & $\%$ & $0.0 \%$ & $28.8 \%$ & $3.8 \%$ & $32.7 \%$ \\
\hline & \multirow{2}{*}{$\geq 70$} & $\mathrm{f}$ & 2 & 13 & 4 & 19 \\
\hline & & $\%$ & $3.8 \%$ & $25.0 \%$ & $7.7 \%$ & $36.5 \%$ \\
\hline \multirow{2}{*}{\multicolumn{2}{|c|}{ Total }} & f & 2 & 40 & 10 & 52 \\
\hline & & $\%$ & $3.8 \%$ & $76.9 \%$ & $19.2 \%$ & $100.0 \%$ \\
\hline
\end{tabular}

Table (4) indicates that $53.8 \%$ of elderly who are 60 years old and more have moderate levels of depressive symptoms; and only $7.7 \%$ of fifties and seventies have severe level.

Table 5: Distribution in levels of depressive symptoms according to the Levels of Education of elderly people

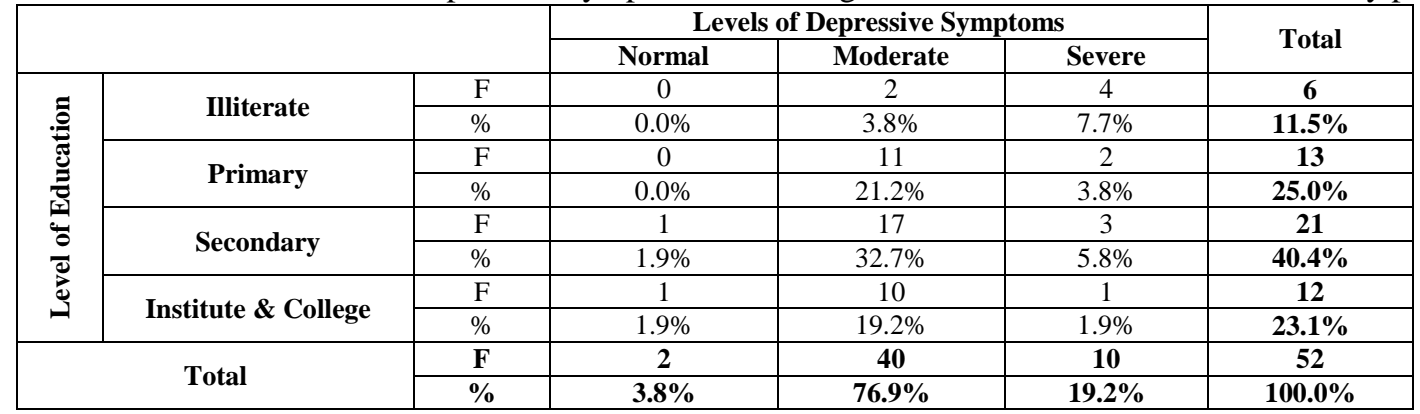

Results of table (5) reveal that $21.2 \%$ of primary school, $32.7 \%$ of secondary school and $19.2 \%$ of institute and college levels of education have moderate level of depressive symptoms; and only $7.7 \%$ of illiterate and $3.8 \%$ of primary have severe level of depressive symptoms.

Table 6. Distribution in the levels of depressive symptoms according to the Marital Status of elderly people

\begin{tabular}{|c|c|c|c|c|c|c|}
\hline & \multicolumn{3}{|c|}{ Levels of Depressive Symptoms } & \multirow{2}{*}{ Total } \\
\hline & & & Normal & Moderate & Severe & \\
\hline \multirow{8}{*}{ 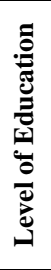 } & \multirow{2}{*}{ Single } & $\mathrm{f}$ & 0 & 1 & 3 & 4 \\
\hline & & $\%$ & $0.0 \%$ & $1.9 \%$ & $5.8 \%$ & $7.7 \%$ \\
\hline & \multirow{2}{*}{ Married } & $\mathrm{f}$ & 2 & 35 & 7 & $\mathbf{4 4}$ \\
\hline & & $\%$ & $3.8 \%$ & $67.3 \%$ & $13.5 \%$ & $84.6 \%$ \\
\hline & \multirow{2}{*}{ Divorced } & $\mathrm{f}$ & 0 & 1 & 0 & 1 \\
\hline & & $\%$ & $0.0 \%$ & $1.9 \%$ & $0.0 \%$ & $1.9 \%$ \\
\hline & \multirow{2}{*}{ Widowed } & $\mathrm{f}$ & 0 & 3 & 0 & 3 \\
\hline & & $\%$ & $0.0 \%$ & $5.8 \%$ & $0.0 \%$ & $5.8 \%$ \\
\hline \multirow{2}{*}{\multicolumn{2}{|c|}{ Total }} & f & 2 & 40 & 10 & 52 \\
\hline & & $\%$ & $3.8 \%$ & $76.9 \%$ & $19.2 \%$ & $100.0 \%$ \\
\hline
\end{tabular}

Table (6) indicates that $67.3 \%$ and $13.5 \%$ of married elderly have moderate and severe levels of depressive symptoms respectively; and only $5.8 \%$ of the singles have severe levels of depressive symptoms.

Table 7: Distribution in levels of depressive symptoms according to the Occupation of elderly people

\begin{tabular}{|c|c|c|c|c|c|c|}
\hline & & & \multicolumn{3}{|c|}{ Levels of Depressive Symptoms } & \multirow{2}{*}{ Total } \\
\hline & & & Normal & Moderate & Severe & \\
\hline \multirow{6}{*}{ 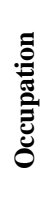 } & \multirow{2}{*}{ Free work } & $\mathrm{f}$ & 0 & 11 & 4 & 15 \\
\hline & & $\%$ & $0.0 \%$ & $21.2 \%$ & $7.7 \%$ & $28.8 \%$ \\
\hline & \multirow{2}{*}{ Retired } & $\mathrm{f}$ & 1 & 22 & 4 & 27 \\
\hline & & $\%$ & $1.9 \%$ & $42.3 \%$ & $7.7 \%$ & $\mathbf{5 1 . 9 \%}$ \\
\hline & \multirow{2}{*}{ House keeper } & $\mathrm{f}$ & 1 & 7 & 2 & 10 \\
\hline & & $\%$ & $1.9 \%$ & $13.5 \%$ & $3.8 \%$ & $19.2 \%$ \\
\hline & \multirow{2}{*}{ Total } & $\mathbf{f}$ & 2 & 40 & 10 & 52 \\
\hline & & $\%$ & $3.8 \%$ & $76.9 \%$ & $19.2 \%$ & $100.0 \%$ \\
\hline
\end{tabular}

Results of table (7) indicate that the moderate levels are distributed among the occupations of elderly $21.2 \%, 42.3 \%$ and

$13.5 \%$ as free work, retired and house keeper respectively. 
Table 8: Association between Demographic characteristics of the elderly people and Depressive symptoms

\begin{tabular}{|c|c|c|c|}
\hline Demographic Characteristics & $\boldsymbol{X}^{\mathbf{2}}$ & df & Sig. \\
\hline Gender & 16.53 & 1 & 0.03 \\
\hline Age & 5.67 & 3 & 0.46 \\
\hline Marital status & 9.57 & 3 & 0.15 \\
\hline Level of Education & 18.57 & 3 & 0.02 \\
\hline Occupation & 2.43 & 2 & 0.66 \\
\hline
\end{tabular}

Table (8) reveals that the study finds a significant association between levels of depressive symptoms and gender $\left(\mathrm{X}^{2}=\right.$ $16.53, \mathrm{p}=0.03)$ and level of education $\left(\mathrm{X}^{2}=18.57, \mathrm{p}=0.02\right)$.

\section{Discussion}

The main aims of present study are to define the various levels of depressive symptoms and find out association between these levels and some socio-demographic characteristics of elderly residing of the nursing homes of Baghdad, Iraq. Socio-demographic information show that out of 52 elderly people in present study, 39 $(75.0 \%)$ are male and $13(25.0 \%)$ are female; $17(32.7 \%)$ are aged between 60 and 69, $19(36.5 \%)$ are 70 and more; $13(25.0 \%)$ are read and write, $21(40.0 \%)$ have secondary school, $12(23.1 \%)$ are with college level of education; $44(84.6 \%)$ are married and only $4(7.7 \%)$ are unmarried (Table 1). Results of the present study reveal that only $3.8 \%$ of the elderly are within normal depressive symptoms, $76.9 \%$ of them are with mild level of depressive symptoms and $19.2 \%$ are with more severe depressive symptoms (Table 2). Distribution of the sample according to the socio-demographic characteristics of the elderly indicates that $73.1 \%$ of male have moderate and more severe levels of depressive symptoms than female have; 60 years old and more, $53.9 \%$ of primary and secondary levels of school, $67.3 \%$ of married, and $42.3 \%$ of retired are likely to have moderate level (Tables 3,4,5,6, \& 7). Data analysis shows that female have more severe level of depressive symptoms than male have $\left(X^{2}=16.35, p=0.03\right)$, the higher level of education the elderly have the severer level of depressive symptoms have those elderly $\left(\mathrm{X}^{2}=18.57, \mathrm{p}=0.02\right)$ (Table 8).

Many previous studies revealed high prevalence of depressive symptoms in elderly living in nursing homes; more than three to four times greater than the non-nursing-homes elderly ${ }^{(15-22)}$. By applying the short form of Geriatric Depression Scale (GDS-15) ${ }^{(1)}$, an additional comprehensive and valuable scoring scheme in rating depressive symptoms, the present study categorized the status of depressive symptoms among elderly sample into three levels: normal, moderate, more severe depressive symptoms according to a 3-cut-off points. In regard to psychiatric epidemiology, the higher prevalence of depressive symptoms in females has been widely documented and has been stated in many studies using various diagnostic instruments or/ and interview approaches $^{(23,24)}$, however, the present results do not agree with the other study, this might be the number of males are more than the number of females. Many earlier studies indicated that depressive symptoms are more common in later life ${ }^{(25,26,27)}$ which agree with the results of present study.

\section{Conclusions and Recommendations}

The present study indicates that the majority of elderly participated are male; about half of them are married; about most of them are 60 years old and more half of them have secondary school and more level of education; about half of participants are retired. Three quarters of elderly have moderate level of depressive symptoms. The study finds a significant relationship between level of depressive symptoms and gender and level of education. The present study recommends for more provision of mental health services for elderly in nursing homes. Increasing in the extent psychosocial support services for elderly is necessary; and referral and follow-up for those who have severe levels of depressive symptoms to specialized hospitals. Further researches upon larger samples and within different governorates of the country are to be done.

\section{References}

[1] Almeida, O. P., \& Almeida, S. A. (1999). Short versions of the geriatric depression scale: a study of their validity for the diagnosis of a major depressive episode according to ICD-10 and DSM-IV. Int J Geriatr Psychiatry; 14 (10): p. 858-865.

[2] Steffens, D., Skook, I., \& Norton, M. C. (2000). Prevalence of depression and its treatment in an elderly population: the Cache County study. Arch Gen Psychiatr; 57: p. 601-607.

[3] Sidik, S. M., Zulkefli, N.A., \& Shah, S. A. (2003). Factors associated with depression among elderly patients in a primary health care clinic in Malaysia. Asia Pacific Family Medicine; 2: p. 148-152.

[4] Krishnan, K. R., Delong, M., Kraemer, H., Carney, R., Spiegel, D., Gordon, C. et al. (2002). Comorbidity of depression with other medical diseases in the elderly. Biol. Psychiatry; 52 (6): p. 559-588.

[5] Beekman, A., Geerlings, S., Deeg, D., et al. (2002). The natural history of late-life depression. Arch Gen Psychiatr; 59: p. 605-611.

[6] Bruce, M. L. (2002). Psychosocial risk factors for depressive disorders in late life. Biol Psychiatry, (52): p. 175-184.

[7] Doraiswamy, P., Khan, Z., Donahue, R., \& Richard, N. E. (2002). The spectrum of quality-of-life impairments in recurrent geriatric depression. J Gerontol Med Sci.;57A: M134-M137.

[8] Al-Shammari, S. A. (1999). Prevalence and correlates of depression among Saudi elderly. Wiley Interscience J: (Abstract).

[9] Mills, T. N., \& Henretta, J. C. (2001). Racial, ethnic and sociodemographic differences in the level of psychosocial distress among older Americans. Research on Ageing; 23 (2): p. 131-152. 
[10] Gazmararian, J., Baker, D., Parker, R., \& Blazer, D. G. (2000). A multivariate analysis of factors associated with depression. Archives of Internal Medicine; 160 (21): p. 3307-3314.

[11] Phillips, E. M., Bodenheimer, C. F., Roig, R. L., \& Cifu, D. X. (2004). Geriatric Rehabilitation.4. Physical medicine and rehabilitation interventions for common age-related disorders and geriatric syndromes. Archives of Physical Medicine and Rehabilitation; 85: p. 18-22.

[12] Austin, E. N., Johnston, Y. A. M., \& Morgan, L. L. (2006). Community gardening in a senior centre: A therapeutic intervention to improve the health of older adults. Therapeutic Recreation Journal; First Quarter: 1.

[13] Alexopoulos, G. S. (2005). Depression in the elderly. The Lancet; 365 (9475): p. 1961-1970.

[14] Sheikh, J. I., Yesavage, J. A. (1986). Geriatric depression scale (GDS): recent evidence and development of a shorter version. Clin Gerontol; 5: p. 165-173.

[15] Doumit, J., \& Nasser, R. (2010). Quality of life and wellbeing of the elderly in Lebanese nursing homes. Int J Health Care Quality Assuran, 23: p. 72-93

[16] Jongenelis, K., Pot, A., Eisses, A., Beekman, A., Kluiter, H., Van Tilburg, W., \& Ribbe, M. (2003). Depression among older nursing home patients. A review]. Tijdschrift Voor Gerontol Geriat, 34:52.

[17] Kramer D, Allgaier A-K, Fejtkova S, Mergl R,Hegerl U (2009). Depression in nursing homes: prevalence, recognition, and treatment. Int J Psychiat Med, 39: p. 345-358.

[18] Nazemi et al. (2013). Depression, Prevalence and Some Risk Factors in Elderly Nursing Homes in Tehran, Iran; Iranian Journal of Public Health 42(6): p. 559-569

[19] Snowdon, J., Rosengren, D., Daniel, F., \& Suyasa M. (2011). Australia's use of the Cornell scale to screen for depression in nursing homes. Aust J Ageing, 30: p. 33-36.

[20] Briones, D. F., Heller, P. L., Carcoba, L. M., Weisman, H. W., Ledger, E. M., \& Escamilla, M. A. (2011). Health-Related Conditions and Depression in Elderly Mexican American and Non-Hispanic White Residents of a United States-Mexico Border County: Moderating Effects of Educational Attainment. Depress Res Treat.

[21] Bruce, M. L., McAvay, G. J., Raue, P. J., Brown, E. L., Meyers, B. S., Keohane, D. J., Jagoda, D. R.,\& Weber, C. (2002). Major depression in elderly home health care patients. Am J Psychiat, 159: p. 1367-1374.

[22] Tabrizi, M. H. (1988). Depression in elderly who live in Nursing Homes in comparison with this vulnerable group who live at their homes. Master Thesis. Iran University of Medical sciences

[23] Nolen-Hoeksema, S. (2001). Gender differences in depression. Curr Direct Psychol Sci, 10:173-176.

[24] Dozeman, E., van Schaik, D., Beekman, A., Stalman, W., Bosmans, J., \& van Marwijk, H. (2007). Depression and anxiety, an Indicated Prevention (DIP) protocol in homes for the elderly: feasibility and (cost) effectiveness of a stepped care programme. BMC Geriatrics, 7: p. 6-11.

[25] Jongenelis, K., Pot, A., Eisses, A., Beekman, A., Kluiter, H., \& Ribbe, M. (2004). Prevalence and risk indicators of depression in elderly nursing home patients: the AGED study. J Affect Disorders, 83: p. 135-142.

[26] Boorsma, M., Joling, K., Dussel, M., Ribbe, M., Frijters, D., van Marwijk, H. W., Nijpels, G., \& van Hout, H. (2012). The Incidence of Depression and Its Risk Factors in Dutch Nursing Homes and Residential Care Homes. AmJ Geriatr Psych, 20(11): p. 932-942.

[27] Etemadi, A., \& Ahmadi, K. (2009). Psychological Disorders of Elderly Home Residents. J Appl Sci, 9: p. 549-554. 